\title{
Iniciação científica na escola: uma abordagem pluralista
}

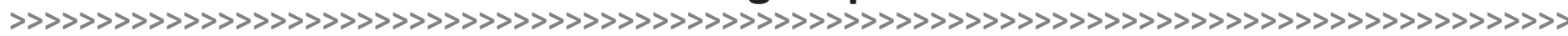

\author{
Luiz Davi Mazzei*
}

\section{Resumo:}

Este texto propõe uma discussão sobre o que é a ciência e qual a sua função na sociedade contemporânea. Para tanto, tomamos como principal suporte teórico a filosofia de Paul Feyerabend. Através de uma análise histórica, questionamos os principais pressupostos do conhecimento científico, principalmente a sua metodologia: o método científico. Ao questionar as atividades de iniciação científica no ambiente escolar, trazemos à discussão a função da escola no que tange à divulgação da ciência e a manutenção de seu status como forma privilegiada de conhecimento.

\section{Palavras-chave:}

Ciência. Iniciação científica. Educação científica.

\begin{abstract}
:
This paper proposes a discussion about what science is and what its function in contemporary society. To support this idea, we take as the main theoretical support the philosophy of Paul Feyerabend. Through a historical analysis questioning the main assumptions of scientific knowledge, particularly its methodology: the scientific method. By questioning the activities of scientific research in the school environment, we bring to the discussion the role of the school in relation to the dissemination of science and the maintenance of its status as a privileged form of knowledge
\end{abstract}

\section{Keywords:}

Science. Scientific research. Scientific education.

\section{Introdução}

Neste texto, pretendo trazer à discussão a prática da iniciação científica na escola. Não tenho como objetivo fazer uma apologia à implementação dessa prática nem fazer um tratado para desacreditar o tema. Acredito que a iniciação científica é uma prática que atualmente goza de certa popularidade; e, sua implementação nas escolas, muitas vezes, deve-se mais à propaganda do que a uma reflexão sobre o assunto. Neste texto, $o$ que proponho é uma análise criteriosa do assunto que, a meu ver, deveria ser feita antes de aderirmos a qualquer prática. Para subsidiar essa análise, trago à discussão alguns elementos sobre os quais considero importante que tenhamos clareza: o que significa ser científico? Para responder a isso, precisamos responder à pergunta "O que é Ciência?" e também "Por que a Ciência é tão importante?”. Ao tentar responder a essas questões,

\footnotetext{
* > Professor do Colégio de Aplicação da Universidade Federal do Rio Grande do Sul (UFRGS). Contato: Idmazzei@gmail.com.
} 
será necessário analisarmos também o método científico e a filosofia que subjaz a ele, o racionalismo. A função da educação, no que tange à divulgação científica e à manutenção do status quo, também precisa ser discutida. Para tanto, utilizarei como referência principal as ideias consideradas 'anarquistas' de Paul Feyerabend, no que diz respeito à Ciência e ao seu status de forma de conhecimento privilegiada.

\section{A Ciência e o Conhecimento Científico como formas privilegiadas de compreender o mundo}

Afinal, o que é Ciência? O que é o conhecimento científico? A resposta a essas perguntas parece ser bastante difícil, pois muitas respostas são possíveis. Para Feyerabend (2011, p. 91) “[...] cada escola na Filosofia da Ciência dá uma descrição diferente daquilo que é Ciência e como ela funciona.” E, de fato, se perguntarmos às pessoas - professores, alunos, pais, comunidade em geral - "O que é Ciência?" teremos uma grande variedade de respostas. Vejamos um exemplo: se perguntarmos aos professores de diferentes disciplinas escolares - Biologia, Matemática, Física, História, Sociologia, Geografia etc. - todos dirão que a disciplina que ministram é uma Ciência, e, provavelmente, farão a distinção: essa é uma ciência exata, aquela outra é uma ciência humana. Como pode um mesmo termo - Ciência - abrigar assuntos ou objetos de estudo tão distintos quanto as células, os conjuntos numéricos, os fatos históricos, a relatividade, e ainda assim ser entendida como uma única entidade: a Ciência? Vejamos como procede a Ciência.

A Ciência distingue aquilo que é real - o que existe independentemente de nossa vontade - e o que é irreal - fruto de devaneios e desejos particulares. Mas, como atividade humana, a Ciência está sujeita às tradições particulares dos cientistas e às suas idiossincrasias. Dessa maneira, como diz Feyerabend (2009, p. 151): “A 'realidade' que a ciência supostamente define e usa para 'eliminar' os ingredientes mais desordenados do nosso mundo está constantemente sendo redefinida para enquadrar-se à tendência em voga no momento.” A Ciência, como todas as demais atividades humanas - as artes, a religião etc. - está em constante transformação, por conta da própria natureza histórica do homem. Feyerabend (2001, p. 94) diz que “[...] 'fatos', 'leis', 'princípios' da ciência e, por esse motivo, de qualquer sistema de conhecimento, são resultados de decisões práticas, ou simplesmente de um certo modo de viver - não de intuições teoréticas somente.” A Ciência moderna, usualmente, conforma-se aos ditames do racionalismo crítico como abordagem adequada ao seu desenvolvimento. Porém,

O conhecimento como é definido pelos racionalistas - conhecimento objetivo e emotivamente asséptico, cujos ingredientes possam ser todos registrados em enunciados claros - não é o único gênero de conhecimento, nem mesmo na ciência. (FEYERABEND, 2001, p. 81)

As tentativas do racionalismo, como uma tradição teórica ${ }^{2}$, de fazer da ciência o

$2>$ Na denominação proposta por Feyerabend, tradições teóricas consideram o conhecimento teórico como único conhecimento válido, sujeito a regras universais. Já as tradições históricas incorporam outras formas de conhecimento além do conhecimento teórico. cimento objetivo, isento de tradições particulares e alheio à ação do próprio cientista, fracassa, pela impossibilidade de se retirar a Ciência do campo das atividades humanas. Feyerabend diz que:

As tradições teóricas se opõem às tradições históricas em intenção, mas não de fato. Ao tentar criar um conhecimento que difere do 'mero' conhecimento histórico ou empírico, elas conseguiram encontrar formulações (teorias, fórmulas) que parecem 
objetivas, universais e logicamente rigorosas, mas que são usadas e, no uso, são interpretadas de uma maneira que entra em conflito com todas essas propriedades. (FEYERABEND, 2009, p. 153, grifos do autor)

Para Feyerabend, o racionalismo, assim como as demais tradições teóricas, é uma tradição histórica que, pela postura (ou arrogância) de seus membros, parece assumir dimensões atemporais e a-históricas, transcendendo os limites de sua condição, arvorandose em juiz externo e objetivo das demais tradições.

Concordo com Feyerabend, que não considera nem a Ciência como forma privilegiada de conhecimento nem o racionalismo como a abordagem mais adequada ao desenvolvimento do conhecimento; não são melhores nem piores do que as demais formas. Entretanto, a sociedade ocidental dá grande valor à Ciência e parece tê-la elegido como a única forma válida de conhecimento. Essa forma de pensar, de acordo com Feyerabend (2009, p. 146), ainda hoje, é encontrada em cientistas que acreditam que "[...] afirmações científicas supostamente descrevem fatos e leis que existem e governam os eventos, não importa o que qualquer um possa pensar delas." Entretanto, Feyerabend argumenta que as próprias afirmações feitas pelos cientistas são produtos humanos e, como tal, certamente não são independentes do pensamento e da ação humana. Ele diz que:

Mesmo as teorias mais abstratas, embora ahistóricas em intenção e formulação, são históricas no uso: a ciência e seus predecessores filosóficos são partes de tradições históricas especiais, e não entidades que transcendem toda a história.(FEYERABEND, 2009 , p. 147, grifos do autor)

Todas as ações humanas, tal como a religião, a ciência e o racionalismo, por exemplo, estão de acordo com muitos fatos, mas escondem (ou tentam esconder) muitas inconsistências e contradições. Ao entender a Ciência e o racionalismo como tradições, e não da forma dogmática como fazem os racionalistas, Feyerabend compara a Ciência contemporânea com a religião na Idade Média. A defesa dos padrões de racionalidade - tais como a exigência de que as teorias sejam consistentes com todos os fatos, não aceitar a introdução de hipóteses ad-hoc - como únicos árbitros na validação de argumentos é muito próxima dos argumentos da Igreja ao julgar casos de bruxaria. Hoje em dia, muitas formas de conhecimento não são valorizadas nem aceitas (por vezes, até mesmo, descartadas) por não serem científicas. Por "não ser científico", podemos entender não estar de acordo com as regras metodológicas, com os padrões racionais que, para Popper, delimitam o campo do conhecimento científico. De maneira muito semelhante, na Idade Média, o que não estivesse de acordo com os métodos e padrões da Igreja era classificado como bruxaria. E, tal como a sociedade medieval, que, por influência da Igreja, condenava a 'bruxaria', atualmente, a sociedade contemporânea condena ao ostracismo as formas de conhecimento 'não científicas', assim rotuladas por não se conformarem aos ditames d' "O Método Científico" - porém, na prática, são frequentemente violados. Em sua crítica à supremacia da Ciência sobre as outras formas de conhecimento e do racionalismo crítico como a abordagem que lhe é adequada, Feyerabend examina a posição dos membros da religião, comparando-a com a postura dos membros do racionalismo:

Praticamente nenhuma religião apresentou-se tão-só como algo que valia a pena experimentar. A reivindicação é muito mais forte: a religião é a verdade, tudo o mais é erro e aqueles que sabem disso, que o compreendem, mas ainda o rejeitam são corrompidos até o cerne (ou são idiotas incorrigíveis). (FEYERABEND 2003, p. 294) 
Feyerabend salienta que nessa reivindicação feita pela religião (bastante similar à feita pela Ciência ocidental contemporânea) existem dois elementos importantes, quais sejam: Primeiro, faz-se a distinção entre práticas, tradições e um domínio diferente, que age sobre as tradições e práticas de maneira externa, sem constituir-se, ele próprio, em uma tradição ou uma prática. Segundo, a explicação da estrutura desse domínio especializado, 'superior', como algo externo a todas as tradições e capaz de fornecer um meio de melhorá-las, justifica - sem qualquer argumento racional - sua superioridade e obediência. O primeiro elemento subentende a crença na existência de regras e exigências "objetivas" e independentes de qualquer tradição. Essa crença, de acordo com Feyerabend (1993, p. 296) “[...] desempenha um papel importante no racionalismo que é a forma secularizada da crença no poder da palavra de Deus”.

\section{A pretensa unicidade metodológica da ciência}

Nos anos finais do ensino fundamental, há a disciplina de Ciências, que envolve os conhecimentos que no ensino médio serão desenvolvidos nas disciplinas de Biologia, Química e Física. Disciplinas que atualmente estão agrupadas no que o Ministério da Educação chama de Ciências da Natureza. São as Ciências empíricas, de laboratório. A elas corresponde a visão comum do cientista: um sujeito trancado num laboratório, muito inteligente, beirando os limites da loucura. Ao nos referirmos a um cientista, poucas pessoas imaginam um historiador ou um geógrafo. Entretanto, se a História e a Geografia são ciências, os profissionais dessas disciplinas tornam-se, por força lógica, cientistas.

Esses exemplos procuram suscitar um debate sobre a dificuldade enfrentada para sabermos o que é Ciência e, consequentemente, o que significa ser científico. A solução encontrada para esse problema foi uma solução metodológica: a Ciência utiliza um conjunto de procedimentos e regras, objetivos, que são universais e aplicáveis a qualquer campo do saber que seja científico: o Método Científico. A aplicação do método, e não o objeto de estudo, é o que garante a (pseudo) unidade da Ciência. Assim, todas as ciências, sejam elas exatas, da natureza ou humanas, empregariam o Método Científico. Esse método científico - cuja filosofia subjacente é o racionalismo crítico (que tem no racionalismo de Popper ${ }^{3}$ sua face mais 'liberal') propõe procedimentos a serem seguidos por aqueles que pretendem fazer Ciência.

$\mathrm{Na}$ visão racionalista ocidental, presente ainda hoje nas escolas, o desenvolvimento da Ciência ocorre a partir de um problema. O significado de problema, nessa visão, não está associado à curiosidade ou a alguma outra atividade criativa. Problema, nessa visão, é uma situação que decorre da não satisfação de alguma expectativa teórica, da observação de alguma irregularidade. Pode-se dizer que, na visão do racionalista crítico, o problema é sempre um 'resultado teorético', o resultado de fatos que contradigam determinadas expectativas teóricas. A teoria molda, assim, os fatos, e, os elementos que serão observados desse fato dependem muito mais dos pressupostos teóricos desse observador do que de sua capacidade de observação. Feyerabend (1989, p. 271) diz que para o racionalista “[...]

3 > Para Karl Popper, a ciência é conhecimento conjectural, falseável. Não há, para Popper, teorias verdadeiras, há apenas teorias ainda não falseadas. $O$ desenvolvimento do conhecimento científico, em sua visão, se dá através do debate crítico e do enfrentamento entre teorias conflitantes. O conhecimento científico deve ser formulado em linguagem objetiva e ter validade universal. Ver mais em Popper, K. Conhecimento Objetivo. existe o fato da irregularidade porque havia uma expectativa de regularidade. $\mathrm{O}$ termo 'irregularidade' só adquire sentido em face de uma regra”.

Após a definição do problema, que será formulado de maneira objetiva, utilizando termos que descrevam o fato 'independente de qualquer outra teoria alternativa', passase, segundo Popper, à tentativa de solução do problema. No dizer de Feyerabend (1989, p. 272), segundo os procedimentos racionalistas, “[...] resolver um problema equivale a inventar uma teoria relevante, falseável (em grau maior do que qualquer outra teoria alternativa), porém ainda não falseada." Ao encontrarmos uma solução para o problema (uma teoria com mais conteúdo e, consequentemente, mais falseável), submetemos à 
crítica a solução encontrada. Nesse momento de crítica, pode ocorrer uma entre duas situações: se a crítica é bem sucedida, ela afasta de uma vez a solução (teoria) anterior; se a crítica é mal sucedida, a teoria permanece sendo alvo de novas críticas. O primeiro caso - a crítica é bem sucedida - deve também responder ao problema de explicar porque a teoria havia se mantido aceitável até então e as razões pelas quais essa teoria deixou de ser satisfatória. A solução desse problema consiste em encontrar uma teoria que, ao mesmo tempo, preserve as consequências aceitáveis da teoria antiga, corrija os erros que essa teoria apresentava e possibilite antever novos fatos até então impensados. A teoria bem sucedida deve satisfazer tais exigências.

Essa visão de problema e de como resolvê-lo pode ser facilmente encontrada nas atividades escolares de iniciação científica: os alunos iniciam seu projeto com a definição de um problema e elaboram hipóteses que possam ser corroboradas (ou refutadas) após sua pesquisa, seja ela experimental ou teórica. Finalmente, apresentam o resultado a uma banca de "especialistas", que avaliam não o resultado apresentado, mas se o método foi corretamente aplicado. O trabalho assim realizado será, indubitavelmente, científico. A própria escolha do assunto a ser investigado é limitada, uma vez que o problema deverá surgir de uma atividade teórica. Dessa forma, muitos assuntos/temas que surgem de atividades práticas e lúdicas - tais como a poesia e a arte - deixam de fazer parte da iniciação científica, pois não são "ciência"4.

Os procedimentos estabelecidos no Método Científico presentes nas atividades de iniciação científica, tais como: objetividade, universalidade e uso de fatos que estejam de acordo com as observações e teorias são criticados por Feyerabend:

A ideia de conduzir os negócios da ciência com o auxílio de um método que encerre princípios firmes, imutáveis e incondicionalmente obrigatórios vê-se diante de considerável dificuldade, quando posta em confronto com os resultados da pesquisa histórica. Verificamos, fazendo um confronto, que não há uma só regra, embora plausível e bem fundada na epistemologia, que deixe de ser violada em algum momento. (FEYERABEND, 1989, p. 29 )

$\mathrm{Na}$ sua crítica à racionalidade (entendida aqui em termos popperianos como racionalidade única, com validade universal), que subjaz aos procedimentos adotados no Método Científico, Feyerabend argumenta apresentando contrarregras que vão contra as regras estabelecidas e aceitas pelo racionalismo crítico como válidas na Ciência. As contrarregras sugerem proceder contraindutivamente, pois podemos considerar que o modelo racionalista é um modelo indutivo, na medida em que estabelece a experiência (particular) como juiz de teorias (universais). E, procedemos contraindutivamente introduzindo e elaborando hipóteses que não estejam de acordo com teorias aceitas ou com fatos conhecidos. Essa contrarregra opõe-se ao empirismo e a um aspecto importante, comum a todas as teorias de confirmação e corroboração:

Consideremos a regra segundo a qual é a 'experiência' ou são os 'fatos' ou são os 'resultados experimentais' que medem o êxito de nossas teorias, a regra segundo a qual uma concordância entre a teoria e os 'dados' favorece a teoria (ou não modifica a situação), ao passo que uma discordância ameaça a teoria e nos força, por vezes, a eliminá-la. (FEYERABEND, 1989, p. 39)

A adoção de uma atitude metodológica pluralista, que contraria a ideia de método único, que utiliza o confronto entre teorias 'conflitivas' é, para Feyerabend, uma das maneiras pelas quais a Ciência avançou ao longo da história:
4 > Esse modelo de iniciação cientifica que trago à discussão (felizmente) não é o único modelo que encontramos nas escolas. Há práticas científicas escolares que possibilitam aos envolvidos extrapolar os limites da "ciência", adotarem procedimentos menos formais e abordarem problemas "não científicos". 
O conhecimento não é uma série de teorias coerentes, a convergir para uma doutrina ideal; não é um gradual aproximar-se da verdade. É, antes, um oceano de alternativas mutuamente incompatíveis (e, talvez, até mesmo incomensuráveis), onde cada teoria singular, cada conto de fadas, cada mito que seja parte do todo força as demais partes a manterem a articulação maior, fazendo com que todos concorram, através desse processo de competição, para o desenvolvimento de nossa consciência (FEYERABEND, 1989, p. 40).

O confronto de uma teoria com teorias incompatíveis - e não a eliminação dessas pode auxiliar no desenvolvimento de novas teorias e na construção de argumentos fortes a favor dessa teoria.

A contrarregra proposta por Feyerabend (1989, p. 41) de aceitar hipóteses que contradigam ou, pelo menos, que não estejam de acordo, com as observações, com os fatos e resultados experimentais, está de acordo com o fato de que "[...] não há uma única teoria digna de interesse que esteja em harmonia com todos os fatos conhecidos que se situam em seu domínio." Segundo Feyerabend, a exigência de que as novas hipóteses devam estar ajustadas a teorias já aceitas é chamada "condição de coerência" e traz consigo o "princípio da autonomia”. Essa condição, ainda conforme Feyerabend, é adotada pela maioria dos filósofos da Ciência do século XX. Contudo, os enunciados factuais e os resultados experimentais trazem sempre pressupostos teoréticos (velada ou abertamente). Nossas observações do mundo "real" estão muito relacionadas a nossos próprios pressupostos teóricos, nossa cultura, nossos preconceitos, ao que nossa cosmologia nos permite ver. $\mathrm{Da}$ mesma maneira, quando observamos um evento - fato, fenômeno, acontecimento - e o relatamos, esses dois processos: a sensação e a expressão do fenômeno observado são partes indissociáveis de um mesmo processo. Essa imbricação entre o fenômeno e a expressão desse fenômeno constitui o que Feyerabend chama de "interpretações naturais". Da mesma maneira, as teorias científicas são elaboradas de acordo com a rede de pressupostos do cientista, a qual inclui pressupostos teóricos, culturais, religiosos etc.

O "princípio da autonomia" consiste em adotar os "fatos relevantes" como juízes da validade de uma teoria, o que supõe que existam fatos e que eles sejam acessíveis, independentemente de considerarmos as alternativas existentes a essa teoria. De acordo com Feyerabend, o princípio da autonomia

Não assevera que a descoberta e a descrição dos fatos sejam independentes de todo o teorizar. Assevera, porém, que é possível chegar a fatos integrados ao conteúdo empírico de uma teoria. Sejam ou não consideradas as alternativas dessa teoria (FEYERABEND, 1989, p. 50).

O princípio da autonomia ignora que as ligações entre os fatos e as teorias são muito mais intimas. Há muitas imbricações na relação entre fatos e teorias. Primeiro, porque toda a descrição de um fato singular depende de uma teoria; segundo, há fatos aos quais só podemos ter acesso se admitirmos alternativas à teoria que queremos testar.

Feyerabend acredita que seguir os princípios do racionalismo, em especial os do racionalismo crítico, não constitui o caminho para o desenvolvimento do conhecimento humano em geral, nem da Ciência, em particular:

Para onde quer que olhemos, sejam quais forem os exemplos por nós considerados, verificamos que os princípios do racionalismo crítico (tomar os falseamentos a sério; aumentar o conteúdo; evitar hipóteses ad-hoc; 'ser honesto' - seja isso o que significar; e assim por diante) e, a fortiori, os princípios do empirismo lógico (ser preciso; apoiar as teorias em medições; evitar ideias vagas e imprecisas; e assim por 
diante) proporcionam inadequada explicação do passado desenvolvimento da ciência e são suscetíveis de prejudicar-lhe o desenvolvimento futuro (FEYERABEND, 1989, p. 278, grifos do autor).

Na defesa de sua posição, Feyerabend apresenta exemplos históricos, com destaque à aceitação das ideias de Galileu, que só ocorreram porque alguns cientistas infringiram, propositada ou involuntariamente, regras metodológicas estabelecidas e aceitas. Para Feyerabend (1989, p. 30) “[...] essa maneira de liberal agir, não é apenas um fato da história da Ciência. É algo razoável e absolutamente necessário para que se desenvolva o conhecimento." Se tal "infração" não tivesse ocorrido, o surgimento de novas teorias, muitas delas com uma cosmologia própria, diferente da vigente à época, seriam impossíveis. Esse ponto de sua argumentação vai contra o racionalismo crítico, que requer a observância estrita às normas metodológicas estabelecidas, uma vez que a obediência irrestrita ao método conduz, invariavelmente, aos mesmos resultados.

\section{A Ciência na escola}

Como visto nas seções anteriores, a Ciência e o conhecimento científico são apenas uma dentre as várias visões de mundo existentes, e o racionalismo crítico é tão somente uma abordagem possível. De acordo com Feyerabend, há muitas e diferentes formas de conhecimento que se fazem presentes em nossa vida, desde os primórdios da civilização humana. Feyerabend diz que além do conhecimento científico,

[...] há outros modos de viver neste mundo. As pessoas intervieram no mundo de múltiplos modos, em parte fisicamente, interferindo de fato nele, em parte conceitualmente, inventando as linguagens e criando no interior delas inferências. Algumas ações encontraram respostas, outras nunca decolaram. Na minha opinião, isso sugere que há uma realidade e que ela é muito mais útil do que tudo quanto presume a maior parte dos objetivistas. Diversas formas de vida e de conhecimento são possíveis porque a realidade permite e até encoraja isso [...] (FEYERABEND, 2001, p. 104).

Tais formas, embora difiram entre si, são necessárias à nossa existência e pertencem a uma tradição enquanto rede de elementos. O conhecimento pode ser estável ou estar em 'um estado de fluxo', pode estar na forma de crenças, na forma de leis - escritas ou orais - na forma de regras gerais que são aprendidas por repetição. O conhecimento ordena os eventos, e, por sua vez, as formas distintas de conhecimento trazem esquemas distintos de ordenamento.

O desenvolvimento do conhecimento pode ocorrer por muitos caminhos diferentes, é muito mais rico e mais complexo do que sugerem os adeptos do Método Científico. O desenvolvimento do conhecimento científico e da Ciência ao longo do tempo se deu por maneiras tão diversas quanto o desenvolvimento das demais atividades humanas. Feyerabend (2003, p. 34) diz que cientistas tentam simplificar a história da Ciência, "[...] tornando-a mais tediosa, mais uniforme, mais 'objetiva' e mais facilmente acessível a tratamento por meio de regras estritas e imutáveis".

A educação científica, tal como presente hoje em dia em nossas escolas, serve a esse objetivo, uma vez que:

Simplifica a "ciência" pela simplificação de seus participantes: primeiro, define-se um campo de pesquisa. Esse campo é separado do restante da história (a física, por exemplo, é separada da metafísica e da teologia) e recebe uma lógica própria. Um treinamento completo em tal "lógica" condiciona então aqueles que trabalham nesse 
campo; torna suas ações mais uniformes e também congela grandes porções do processo histórico (FEYERABEND, 2003, p. 34, grifos do autor).

Esse treinamento tem por objetivo deixar de fora todas as características inerentes ao indivíduo: a religião, o senso de humor, a imaginação, os desejos, enfim, as caracterís ticas humanas. Torna a Ciência uma atividade asséptica e objetiva.

Precisamos nos perguntar se esse procedimento é desejável. A meu ver, não parece interessante deixar que uma forma de ver o mundo domine as demais, restringindo nossas opções. A natureza oferece-nos uma abundância de opções e restringir esse enorme contingente de possibilidades a uma forma apenas não parece adequado; menos ainda em nossas escolas. Outra razão é apresentada por Feyerabend:

Uma educação científica, como antes descrita (e como praticada em nossas escolas), não pode ser conciliada com uma atitude humanista. Está em conflito 'com o cultivo da individualidade, a única coisa que produz ou pode produzir seres humanos bem desenvolvidos' (FEYERABEND, 2003, p. 35).

Se acreditarmos que um dos pilares da educação em nossas escolas é a defesa da liberdade, o respeito à diversidade, uma educação científica tal como se apresenta não só não é desejável como também é contrária a tais princípios.

\begin{abstract}
A tentativa de fazer crescer a liberdade, de levar uma vida plena e gratificante e a tentativa correspondente de descobrir os segredos da natureza e do homem acarretam, portanto, a rejeição de todos os padrões universais e de todas as tradições rígidas. (Naturalmente, acarretam também a rejeição de grande parte da ciência contemporânea) (FEYERABEND, 2003, p. 35).
\end{abstract}

Não pretendo, entretanto, negar a importância do conhecimento científico e da Ciência, mas apenas ressaltar que tais formas constituem uma possibilidade - dentre tantas - e não a única opção possível, como querem nos fazer pensar alguns cientistas. Concordo com Feyerabend, quando ele diz que:

\begin{abstract}
A educação geral deve preparar os cidadãos para escolher entre os padrões, ou achar seu caminho em uma sociedade que contém grupos comprometidos com vários padrões, mas não deve em condição alguma subjugar a mente deles de modo que se conformem aos padrões de algum grupo particular. Os padrões serão considerados, serão discutidos. As crianças serão encorajadas a ter proficiência nos assuntos mais importantes, mas só como se tem proficiência em um jogo, ou seja, sem compromisso sério e sem roubar a mente de sua capacidade de jogar também outros jogos. (FEYERABEND, 2003, p. 224, grifos do autor)
\end{abstract}

A escola deve estar integrada ao contexto social, político e econômico no qual se insere. Assim, a escolha de uma prática em detrimento das demais faz dela um local de exclusão, o que vai contra a própria concepção de educação que pretendemos. 


\section{Considerações finais}

Chegando ao final deste texto, acredito ter ressaltado que a iniciação científica na escola é uma possibilidade e que a Ciência e o conhecimento científico são pontos de vista em relação à abundância de opções que a natureza nos oferece. Isso significa que a adoção desse ou de outro ponto de vista deve ser precedida por uma reflexão consciente, na qual as outras alternativas sejam também consideradas. Essa reflexão deve ser feita tanto pelos que comandam a educação (educadores) quanto pelos que serão educados. Uma educação comprometida com a liberdade, com a autonomia e com a formação de pessoas comprometidas com a construção de um mundo mais justo e humanitário não deve ser um processo impositivo, no qual apenas uma visão seja válida. Dada a abundância de opções que nos apresenta a realidade, negar aos nossos alunos a possibilidade de escolha significa torná-los escravos de um destino escolhido por nós. Uma educação que adote a pluralidade metodológica, que aborde as diferentes formas de ver o mundo e que seja capaz de aceitar as diferentes cosmologias, parece ser o caminho mais adequado. A Ciência, enquanto uma maneira de ver (e viver) o mundo, deve, sim, estar presente na escola. O que proponho é uma discussão sobre se ver (e viver) o mundo cientificamente é mesmo a única maneira que deve ser desenvolvida na escola. E, se o for, que tenhamos consciência de sua intrínseca pluralidade, que a reflexão histórica revela.

\section{Referências}

FEYERABEND, Paul. A Ciência em uma sociedade livre. São Paulo: Unesp, 2011 . Adeus à Razão. São Paulo: Unesp, 2009. . Contra o Método. São Paulo: Unesp, 2003. . Diálogos sobre o Conhecimento. São Paulo: Perspectiva, 2001. . Contra o Método. Lisboa: Relógio D’Água, 1993.

. Contra o Método. Rio de Janeiro: Francisco Alves, 1989.

POPPER, Karl. Conhecimento Objetivo. Belo Horizonte: Itatiaia, 1999. . A lógica da pesquisa científica. 15 ed. São Paulo: Cultrix, 2011. 